\title{
Pamukta (Gossypium hirsutum L.) Hasadın Kalite Üzerine Etkisi
}

\section{Hüseyin TERZi ${ }^{1}$ (D), Mustafa Ali KAYNAK ${ }^{* 1}$ \\ ${ }^{1}$ Aydın Adnan Menderes Üniversitesi Ziraat Fakültesi Tarla Bitkileri Bölümü, Aydın}

Öz: Bu çalışma pamukta makinalı ve elle hasadın kalite üzerine etkilerini belirlemek amacıyla, Aydın ili, Efeler, Koçarlı, İncirliova, Söke, Germencik ve Nazilli ilçelerinde 2016 üretim yılında yapılmıştır. Çalışmada Gloria pamuk çeşidi bitki materyali olarak kullanılmıştır. Deneme tesadüf parselleri deneme desenine göre iki faktörlü olarak yürütülmüştür. Çalışmada, lokasyonlar (ilçeler) arasında çırçır randımanı, lif inceliği, lif uzunluğu, lif kopma dayanıkııı̆ı̆ ve elyaf yansıma değeri özellikleri yönünden, önemli oranda, hasat yöntemleri arasında ise çıçıır randımanı, lif inceliği, lif olgunluğu, lif kopma dayanıklıı̆̆ı, elyaf yansıma değeri, elyaf sarılık değeri ve lifteki çepel sayısı özellikleri yönünden önemli oranda farkılık olduğu, lokasyonXhasat yöntemi interaksiyonunun ise, çırçır randımanı, lif inceliği, lif olgunluğu, lif uzunluğu, lif kopma dayanıklılığı, özelliklerinde önemli olduğu saptanmıştır. Ayrıca tüm lokasyonlarda makine ile toplanan pamukların lif rengi 1-2 derece daha düşük çıkmıştır. Çalışmada, çırçır randımanı, lif olgunluğu, lif kopma dayanıklılığı, elyaf yansıma değeri, lif çepel sayısı ve lif rengi özellikleri yönünden elle hasadın, lif inceliği ve elyaf sarılık değeri özellikleri yönünden ise makinalı hasadın daha uygun olduğu saptanmışıı.

Anahtar Kelimeler: pamuk, hasat, kalite

\section{The Effect of Harvesting on Quality in Cotton (Gossypium hirsutum L.)}

\begin{abstract}
The study was carried out to determine effect of harvest methods on fiber quality in cotton grown in Efeler, Kocarli, Incirliova, Soke, Germencik and Nazilli districts of Aydin province, Turkey. The experiment was arranged as randomized complete plots design with two factors. In this study Gloria was used as research material. The effect of locations on ginning percentage, fiber fineness, fiber strength, fiber length and fiber brightness were found to be significant. The ginning percentage, fiber fineness, fiber maturity, fiber strength, color reflectance, yellowness rate of fiber and trash count in fiber were influenced significantly by harvest methods. A significant locationXharvest methods interactions were determined for ginning percentage, fiber fineness, maturity degree of fiber, fiber length and fiber strength measurements. Besides, the lowest fiber color was found in the harvest machine at all locations. The result showed that hand harvest was more appropriate than machine harvest method especially for ginning percentage, maturity degree of fiber, fiber strength, fiber brightness, trash count in fiber and fiber color. On the other hand, machine harvest time was found to be appropriate in terms of yellowness rate of fiber and fiber fineness.
\end{abstract}

Keywords: cotton, harvest, quality

\section{Giriş}

Pamukta lif kalite özelliklerini, çeşidin genetik yapısı yanında, iklim ve toprak koşulları, zararlı baskısı, gelişme döneminin uzunluğu, hasat ve çırçırlama yöntemleri ve zamanları da etkileyebilmektedir (Meredith, 1984).

Makinalı pamuk hasadının pamuğun lif kalite özellikleri üzerine olan etkisi ile ilgili ülkemizde yürütülen çalışmalarda, makinalı pamuk hasadında lif kalite özellikleri yönünden herhangi bir farklılığın olmadığı, makinalı hasatta çepel oranının elle hasada göre daha yüksek bulunduğu, makinalı hasattan elde edilen pamuğun ek temizleme sistemi olmayan rollergin çırçır makinasında çırçırlanmasından dolayı, renk derecesinde bir derece azalmaya neden olduğu (Evcim ve Öz, 1998) görülmüştür. Farklı pamuk çeşidi ve farklı yaprak döktürücülerin uygulandığı bir diğer çalışmada, hasat makinasının pamuğun lif kalite özelliklerine önemli bir etkisinin olmadığı (Öz ve Evcim, 2002), makinalı hasatta tarla kayıplarının elle hasada oranla \%1 ve 2 oranında daha yüksek bulunduğu (Evcim, 1999), makinalı pamuk hasadında lif pamuğun renginde kısmi değişim olabileceğini ve ürün kaybının \%3-12 arasında değişebileceğini ve hasatta yabancı madde oranının \% 4-5 civarında olduğu (Tuncer ve Işık, 1999), mevcut standart çeşitlerle makinalı hasadın yapılabileceği (Kaynak ve Çopur, 1999), iyi bir hasat ve sonuçta iyi bir kalite elde edebilmek için yaprak döktürme işleminin iyi yapılması gerektiği (Mayfield, 1996) bildirilmektedir.

Türkiye'de pamuk tarımında elle hasat döneminde yaşanan işçi teminindeki zorluklar ve işgücü maliyetlerinin yükselmesi üreticileri makinalı hasada doğru yönlendirmektedir (Işık ve Sabancı, 1988; Evcim ve Öz, 1997). Evcim (1996), Türkiye'de yüksek kapasiteli hasat makinalarının kullanıldığı bu makinaların büyük üretim alanlarında ve uzun kullanım sürelerinde ekonomik olduğunu ifade etmiştir. Ören ve Yaşar (2003), makineli hasadın hasat giderlerini \%29 oranında azaltmasına karşın, pamuk ekili alanların küçük ve parçalı yapıda olması, hasat

Sorumlu Yazar: mkaynak@adu.edu.tr Bu çalışma yüksek lisans tez ürünüdür ve Aydın Adnan Menderes Üniversitesi Bilimsel Araştırma Projeleri Koordinatörlüğünce desteklenmiştir.

Geliş Tarihi: 5 Eylül 2018

Kabul Tarihi: 3 Mayıs 2019 
makinesi fiyatlarının yüksek olması, yeterli sayıda pamuk hasat makinesi operatörü bulunmaması ve ücretlerin yüksek olmasının makineli hasat uygulamasının yaygınlaşmasında yaşanan sorunlar olduğunu ayrıca makineli hasadın yaygınlaşmasının ise işsizlik sorununa neden olacağını ve yeni istihdam olanaklarının geliştirilmesi gerektiğini belirtmişlerdir.

2017 yılında Ege Bölgesinde 399 adet, Çukurova Bölgesinde 225 adet, Antalya Bölgesinde 6 adet ve Güneydoğu Anadolu Bölgesinde ise 548 adet pamuk toplama makinası bulunmaktadır (Anonim, 2018 ).

Bu çalışma, Aydın ekolojik koşullarında, makinalı ve elle pamuk hasadının lif kalitesi üzerine etkisini belirlemek amacıyla yapılmıştır.

\section{MATERYAL VE YÖNTEM}

\section{Materyal}

Çalışmada, Gosyypium hirsutum L. türüne ait ve bölgemiz standart pamuk çeşitlerinden biri olan Gloria pamuk çeşidi materyal olarak kullanılmıştır. Çalışmada, hasat sırasında elle ve makine ile toplanan kütlü pamuk örnekleri; Efeler, Koçarlı, İncirliova, Söke, Germencik ve Nazilli ilçelerinde üretici tarlalarından temin edilmiştir.

\section{Yöntem}

Çalışma, 2016 üretim yılında, Aydın İli, Efeler, Söke, Germencik, Koçarlı, İncirliova, Nazilli ilçelerinde üretici arazilerinde tesadüf parselleri deneme desenine göre iki faktörlü olarak yürütülmüştür. Denemelerin ekimleri Nisan ve Mayıs ayı içerisinde gerçekleşmiştir. Ekimden sonra arazilerde yapılan tüm kültürel işlemler normal üretim koşullarına göre yapılmıştır. Denemede hasat tarihi, ilçelere ve ekim tarihlerine göre değişmekle birlikte, elle hasat Eylül-Ekim, makinayla hasat ise Ekim-Kasım aylarında yapılmıştır.

Çalışmaların yürütüldüğü tarlalarda öncelikle referans değerlerini belirleyebilmek amacıyla bilimsel esaslara uygun olarak seçilen şeritlerden elle toplamak suretiyle örnekler alınmıştır. Makinenin lif üzerine etkilerinin belirlenebilmesi için ise hasat sonrası makinenin deposundan da örnekler alınmıştır. Örnek alımı sırasında kütlü pamuk örneklerinin nem oranları da belirlenmiştir. Çalışmada, çırçır randımanı, lif uzunluğu, lif inceliği, lif kopma dayanıklılığı, lif olgunluğu, kısa lif içeriği, lif parlaklık derecesi, lif sarılık değeri, lifteki çepel sayısı ve lif rengi özellikleri incelenmiştir. Verilerin istatistik analizi, TARIST programı kullanılarak yapılmıştır.

\section{BULGULAR VE TARTIŞMA}

İncelenen özelliklere ilişkin varyans analizi kareler ortalaması değerleri Çizelge 1'de verilmiştir.

Çizelge 1. İncelenen özelliklere ilişkin varyans analizi kareler ortalaması

\begin{tabular}{|c|c|c|c|c|c|c|c|c|c|}
\hline VK & ÇR & LU & Li & LKD & LO & LPD & LSD & KLi & LÇS \\
\hline Lokasyon & $6.489 * *$ & $5.082 * *$ & $0.102 * *$ & $5.678 * *$ & 0.000 & $2.895^{* *}$ & 0.171 & 0.398 & 160.071 \\
\hline Hasat Y. & $46.217^{* *}$ & 0.063 & $1.428^{* *}$ & $4.941^{*}$ & $0.001 * *$ & $258.077^{* *}$ & $3.685^{* *}$ & 0.750 & $26743.521^{* *}$ \\
\hline Lok.xHY & $1.774^{* *}$ & $1.466 * *$ & $0.140 * *$ & $9.374 * *$ & $0.000 * *$ & 0.970 & 0.145 & 0.401 & 100.371 \\
\hline Hata & 0.222 & 0.304 & 0.024 & 1.113 & 0.000 & 0.757 & 0.095 & 0.259 & 72.062 \\
\hline Genel & 2.032 & 0.931 & 0.075 & 2.559 & 0.000 & 6.482 & 0.184 & 0.300 & 651.914 \\
\hline
\end{tabular}

(VK: Varyasyon kaynağı, HY: Hasat yöntemi, ÇR: Çırçır randımanı, LU: Lif uzunluğu, Li: Lif inceliği, LKD: Lif kopma dayanıklılı̆ı, LO: Lif olgunluğu, LPD: Lif parlaklık derecesi, LSD: Lif sarılık değeri, KLi: Kısa lif içeriği, LÇS: Lifteki çepel sayısı)

*:\%5 seviyesinde önemli **:\% 1 seviyesinde önemli

Çizelge 1'den, çırçır randımanı, lif uzunluğu, lif inceliği, lif kopma dayanıkılığı ve lif parlaklık derecesi yönünden lokasyonlar arasında önemli oranda, çırçır randımanı, lif inceliği, lif kopma dayanıklılığı, lif olgunluğu, lif parlaklık derecesi, lif sarılık değeri ve lifteki çepel sayısı yönünden hasat yöntemleri arasında önemli oranda farklığın olduğu, lokasyonXhasat yöntemi interaksiyonun ise çırçır randımanı, lif uzunluğu, lif inceliği, lif kopma dayanıklılığı ve lif olgunluğu özelliklerinde önemli olduğu görülmektedir.

Çalışmada, çırçır randımanı (\%), lif uzunluğu (mm) ve lif inceliği (micronaire) değerleri ve oluşan gruplar Çizelge 2'de, lif kopma dayanıklılığı (g/tex), lif olgunluğu (\%) ve lif parlaklık derecesi (Rd) değerleri ve oluşan gruplar Çizelge 3'de, lif sarılık değeri (+b), kısa lif içeriği (\%) ve lifteki çepel sayısı (TrCnt) değerleri ve oluşan gruplar ise Çizelge 4 'de verilmiştir.
Çırçır Randımanı (\%): Çizelge 2'de, lokasyonlar çırçır randımanı yönünden değerlendirildiğinde, en yüksek çırçır randımanı ortalaması Söke (\%42.16) ve Germencik (\%41.98) den alınmıştır.

Hasat yöntemi yönünden çırçır randmanını kıyasladığında elle hasatta (\%42.10), makineli hasada (\%40.14) göre daha yüksek çırçır randımanı bulunmuştur. Lokasyonlara göre hasat metotları kıyasladığında elle yapılan hasatlardaki çırçır randımanı oranı makineli hasada göre önemli oranda daha yüksek bulunmuştur. Bu durum, elle yapılan hasatta kütlü pamuk içinde çepel miktarının daha düşük olmasından kaynaklanmış olabilir.

Elle toplanan kütlülerde çırçır randımanı değerinin makinalı hasattan daha yüksek olduğu (Kaynak ve ark., 2000 ve Karademir ve ark., 2005) tarafından da bildirilmektedir. Kechagia (1994), agronomik parametrelerin çoğunu 
Çizelge 2. Çırçır randımanı (\%), lif uzunluğu ( $\mathrm{mm}$ ) ve lif inceliği (micronaire) değerleri ve oluşan gruplar

\begin{tabular}{|c|c|c|c|c|c|c|c|c|c|}
\hline \multirow{3}{*}{ Lokasyon } & \multicolumn{3}{|c|}{ Çırçır Randımanı (\%) } & \multicolumn{3}{|c|}{ Lif Uzunluğu (mm) } & \multicolumn{3}{|c|}{ Lif İnceliği (micronaire) } \\
\hline & \multicolumn{3}{|c|}{ Hasat Yöntemi } & \multicolumn{3}{|c|}{ Hasat Yöntemi } & \multicolumn{3}{|c|}{ Hasat Yöntemi } \\
\hline & Elle & Makine & Ort. & Elle & Makine & Ort. & Elle & Makine & Ort. \\
\hline Söke & 43.52 a $A^{*}$ & 40.80 a B & 42.16 & 30.05 b A & 30.31 bc $A$ & 30.18 & $4.76 a b c A$ & 4.62 a $A$ & 4.69 \\
\hline Efeler & 41.47 b A & 40.27 a B & 40.87 & $30.27 \mathrm{~b} \mathrm{~A}$ & $28.99 \mathrm{~d} \mathrm{~B}$ & 29.63 & $4.75 \mathrm{bc} \mathrm{A}$ & $4.72 \mathrm{a} A$ & 4.74 \\
\hline Koçarlı & $42.15 \mathrm{~b} \mathrm{~A}$ & 40.72 a B & 41.43 & 28.54 с B & $29.76 \mathrm{~cd} \mathrm{~A}$ & 29.15 & $4.95 \mathrm{ab} A$ & 4.64 a B & 4.80 \\
\hline Germencik & 43.02 a $A$ & 40.95 a B & 41.98 & $30.76 \mathrm{ab} A$ & 30.28 bc $A$ & 30.52 & 4.97 a $A$ & $4.52 \mathrm{ab} \mathrm{B}$ & 4.74 \\
\hline İncirliova & 40.37 c A & 39.40 b B & 39.88 & $30.34 \mathrm{~b} \mathrm{~A}$ & $30.80 \mathrm{ab} A$ & 30.57 & $4.68 \mathrm{cA}$ & 4.32 bc B & 4.50 \\
\hline Nazilli & $42.07 \mathrm{~b} \mathrm{~A}$ & 38.70 с B & 40.38 & 31.32 a $A$ & 31.55 a A & 31.44 & $4.97 \mathrm{ab} \mathrm{A}$ & 4.19 c B & 4.58 \\
\hline Ortalama & 42.10 & 40.14 & 41.11 & 30.21 & 30.28 & 30.25 & 4.85 & 4.50 & 4.67 \\
\hline
\end{tabular}

*Küçük harfler, hasat yöntemine göre lokasyonların önem düzeyleri ve oluşturdukları gruplar. Büyük harfler, lokasyonlara göre hasat yönteminin önem düzeyleri ve oluşturdukları gruplar

belirleyen en önemli faktörün çeşit olduğunu vurgularken, Cathey ve ark. (1986), \%30 ve \%40 koza açım döneminde yapılan defoliant uygulamasının çırçır randımanını kontrole göre azalttığını belirtmişlerdir. Dolayısıyla makinalı hasat uygulamasında çırçır randımanın düşük olmasının bir diğer nedeni defoliant uygulamalarının erken yapılmasından kaynaklanmış olabilir.

Lif Uzunluğu (mm): Çizelge 2'de, lokasyonlar lif uzunluğu yönünden değerlendirildiğinde, en uzun liflerin Nazilli (31.44 mm) en kısa lifin ise Koçarlı (29.15 mm) lokasyonundan elde edilmiştir. Lokasyonlara göre lif uzunluğu yönünden hasat yöntemleri kıyaslandığında, elle yapılan hasatlardaki lif uzunluğunun makineli hasada göre önemli olmamakla birlikte daha kısa olduğu saptanmıştır.

Krieg (2002), pamukta lif kalitesi üzerine genotipik ve çevresel etmenlerin birlikte etki ettiğini, bir pamuk örneğinde elyafın kalite özelliklerinin genellikle bu iki etmenin interaksiyonu ile ortaya çıktığını, lif uzunluğu üzerine genotipik etkinin daha önemli bulunduğunu belirtmiştir. Jost (2005), lif uzunluğunun esas olarak genotipik özellikler ile ilişkili olduğunu, Kechagia (1994) kalite ile ilgili hemen hemen tüm özellikleri ve agronomik parametrelerin çoğunu belirleyen en önemli faktörün çeşit olduğunu bildirmişlerdir. Çalışmada, lif uzunluk değerinin hasat yöntemine göre değişmediğini, ancak farklı çevresel etmenlere bağlı olarak lokasyonlara göre bir miktar değiştiği ortaya konmuştur.

Elde edilen bulgular, Evcim (1999)'un makinalı hasadın elle hasada göre lif uzunluğuna etkisinin önemli olmadığını, Kaynak ve ark. (2000)'nin makinalı hasadın lif uzunluğuna etkisinin elle hasattan farksız olduğunu, Öz (2001)'in makinalı hasadın lif uzunluğuna olumsuz bir etkisinin olmadığını, Karademir ve ark. (2005)'in lif uzunluğunun makinalı hasattan önemli oranda etkilenmediğini, Evcim ve ark. (2007)'nin hasat makinasının lif özelliklerine olumsuz bir etkisinin olmadığını ve Sessiz ve ark. (2012)'nin lif uzunluğuna makinalı hasadın elle hasada göre olumsuz etkisinin olmadığını bildiren bulgularıyla uyum içindedir Lif İnceliği (micronaire): Çizelge 2'de, lokasyonlar lif inceliği yönünden değerlendirildiğinde en kalın liflerin Koçarlı (4.80 mic.), en ince liflerin ise İncirliova (4.50 mic.) lokasyonunda olduğu saptanmıştır. Hasat yöntemi yönünden lif inceliği kıyasladığında elle hasatta (4.85 mic.) makineli hasata (4.50 mic.) göre önemli oranda kalın lif elde edilmiştir. Lokasyonlara göre hasat yöntemleri kıyaslandığında elle yapılan hasatlardaki lif inceliği değerinin makineli hasada göre rakamsal olarak daha yüksek bulunmuştur. Diğer bir deyişle elle hasatta lifler daha kalındır.

Çalışmada, hasat yöntemlerinin lif inceliğine önemli etkisinin olduğu saptanmasına karşın, Evcim (1999), Kaynak ve ark. (2000), Öz (2001), Karademir ve ark. (2005) ve Sessiz ve ark. (2012) ise makinalı hasadın elle hasada göre lif inceliğine etkisinin önemli olmadığını belirtmişlerdir. Lokasyonlar arasında lif inceliği yönünden önemli oranda farklılığın olması ekilen çeşit aynı olduğu için daha çok çevresel faktörlerden kaynaklanmaktadır.

Silvertooth (2001), lif inceliğinin öncelikle genotipe bağlı bir karakter olmakla birlikte, çevre şartları ve kültürel işlemlerin de lif inceliği üzerine etkili olduğunu, Özbek (2011), yıllara, çeşitlere ve koza hasat zamanına göre lif inceliğinin farklılık gösterdiğini, Metzer ve Supak (1997), çok erken yapılan defoliant uygulamalarının lif inceliğini azalttığını, Cathey ve ark. (1986), pamukta \%30 ve \%40 koza açım döneminde defoliant uygulamasının lif inceliğini düşürdüğünü bildirmişlerdir.

Lif Kopma Dayanıklılığı (g/tex): Çizelge 3'de, hasat yöntemi yönünden, elle hasatta (35.83 g/tex), makinalı hasata (35.19 g/tex) göre önemli oranda daha yüksek lif kopma dayanıklılığı elde edilmiştir. Lokasyonlara göre lif kopma dayanıklılığı yönünden hasat yöntemleri kıyaslandığında makinalı hasadın sadece Söke ve Koçarlı lokasyonlarında önemli oranda daha fazla sağlam liflere sahip olduğu saptanmıştır.

Araştırmadaki bu değerler ile ilgili Krieg (2002), pamukta lif kalitesi üzerine genotipik ve çevresel etmenlerin birlikte etki ettiği, bir pamuk örneğinde elyafın kalite özellikleri genellikle bu iki etmenin interaksiyonu ile ortaya çıktığını bildirirken, Özbek (2011), koza hasat zamanı ile lif kopma dayanıklılığı arasında kuadritik bir ilişki olduğunu, erken hasat edilen kozalarda düşük olgunluk, geç hasat edilen kozalarda ise çevresel faktörler nedeniyle lif kopma dayanıklılığı değerinde azalma görüldüğünü, Metzer ve Supak (1997), çok erken yapılan defoliant uygulamalarının, lif mukavemetini düşürdüğünü, Silvertooth (1998), uzun 
Çizelge 3. Lif kopma dayanıklılığı (g/tex), lif olgunluğu (\%) ve lif parlaklık derecesi (rd) değerleri ve oluşan gruplar

\begin{tabular}{|c|c|c|c|c|c|c|c|c|c|}
\hline \multirow{3}{*}{ Lokasyon } & \multicolumn{3}{|c|}{ Lif Kopma Dayanıklılığı (g/tex) } & \multicolumn{3}{|c|}{ Lif olgunluğu (\%) } & \multicolumn{3}{|c|}{ Lif Parlaklık Derecesi (Rd) } \\
\hline & \multicolumn{3}{|c|}{ Hasat Yöntemi } & \multicolumn{3}{|c|}{ Hasat Yöntemi } & \multicolumn{3}{|c|}{ Hasat Yöntemi } \\
\hline & Elle & Makine & Ortalama & Elle & Makine & Ortalama & Elle & Makine & Ortalama \\
\hline Efeler & 35.85 a $A$ & 32.20 c B & 34.02 & $0.87 \mathrm{~b} \mathrm{~A}$ & $0.87 \mathrm{ab} A$ & 0.87 & 82.45 & 77.60 & $80.02 \mathrm{a}$ \\
\hline Koçarlı & 34.05 b B & 36.22 a $A$ & 35.13 & $0.87 \mathrm{~b} \mathrm{~A}$ & 0.87 a $A$ & 0.87 & 80.55 & 77.02 & $78.78 \mathrm{ab}$ \\
\hline Germencik & 36.62 a A & 34.42 b B & 35.52 & $0.87 \mathrm{~b} \mathrm{~A}$ & $0.87 \mathrm{ab} \mathrm{A}$ & 0.87 & 81.87 & 77.42 & 79.65 b \\
\hline Ortalama & 35.83 & 35.19 & 35.59 & 0.88 & 0.87 & 0.87 & $81.70 \mathrm{~A}$ & $77.06 \mathrm{~B}$ & 79.39 \\
\hline LSD (\%5) & \multicolumn{3}{|c|}{ Lokasyon X Hasat Yöntemi:1.514 } & \multicolumn{3}{|c|}{ Lokasyon X Hasat Yöntemi :0.008 } & \multicolumn{3}{|c|}{ Lokasyon:0.883, Hasat yön.:1.249 } \\
\hline
\end{tabular}

*Küçük harfler, hasat yöntemine göre lokasyonların önem düzeyleri ve oluşturdukları gruplar. Büyük harfler, lokasyonlara göre hasat yönteminin önem düzeyleri ve oluşturdukları gruplar

süreli aşırı yağışın life zarar verebilen fiziksel ve mikrobiyal herhangi bir faktörün dayanıklılığı azaltabileceğini, fiziksel ve mikrobiyal zararlanmalar, kötü hava koşulları, aşırı çırçırlama elyaf kopma dayanıkılığının azalmasına neden olduğunu, Shurley ve ark. (2004), hasadın gecikmesi ile lif kopma dayanıkılığının azaldığını bildirmişlerdir. Çalışmada, makinalı hasat elle hasata göre en az iki hafta sonra yapıldığından elde edilen bulgular, bu çalışmalarla benzerlik göstermekte, Evcim (1999), Kaynak ve ark. (2000), Öz (2001), Öz ve Evcim (2002), Sessiz ve ark. (2012) hasat yönteminin lif kopma dayanıklılığına önemli etkisinin olmadığı belirten bulgularıyla ise uyum sağlamamaktadır.

Lif Olgunluğu (\%): Çizelge 3’de, hasat yöntemi yönünden lif olgunluğu kıyasladığında elle hasatta (0.88) makineli hasada (0.87) göre daha yüksek lif olgunluğu elde edilmiştir. Lokasyonlara göre hasat yöntemleri kıyaslandığında elle yapılan hasatlardaki lif olgunluğu değeri makineli hasada göre lokasyonlar arasında önemli bulunmamaktadır.

Silvertooth (2001), olgunlaşmamış kozaların hasat edilmesinin elyafta düşük olgunluk değerlerine neden olduğunu, hasatta erken defoliant ve desikant uygulamalarının lif olgunluğunu azalttığını bildirmiştir.

Farklı olgunlukta liflerin birlikte kullanıldığı iplik ya da kumaşın boyar madde alınımı da düzgünsüz olur ve hatalı boyamalar ile renk farklılıkları ortaya çıkar. Bu nedenle lif olgunluğunu dikkate alarak hasat planı yapmak ve erken defoliant uygulamasından kaçınmak gerektiği, (Öktem ve ark., 1999 ) tarafından bildirilmektedir.

Lokasyonlar arasında lif olgunluğu yönünden önemli bir farklılık bulunmamakla birlikte, hasat yöntemi yönünden önemli farklılık gözükmektedir. Lokasyon $\mathrm{x}$ hasat yöntemi arasındaki varyasyon hasat koşulları, hasada yardımcı uygulama zamanı, üretim sezonu boyunca lokasyonlardaki iklimsel faktörleri gibi özelliklerin önemli rol oynadığı söylenebilir.

Lif Parlaklık Derecesi (Rd): Çizelge 3'de, hasat yöntemi yönünden elle hasatta $(81.70 \mathrm{Rd})$, makinalı hasata (77.06 Rd) göre önemli oranda daha yüksek lif parlaklık derecesi elde edilmiştir. Lokasyonlar arasında lif parlaklık derecesi yönünden önemli oranda farklılıklar olduğu, lif parlaklık derecesinin en yüksek Efeler ve Koçarlı lokasyonun da olduğu saptanmıştır. Ayrıca, lokasyonlara göre elle ve 30 makine ile yapılan hasatlarda elle yapılan hasatlardaki lif parlaklık derecesinin arttığı gözlemlenmiştir. Bu varyasyonun oluşmasında lokasyonlardaki hasat koşulları ve hasada yardımcı kimyasal uygulama başarısının önemli rol oynadığı söylenebilir. Çalışmada makinalı hasattaki lif parlaklık derecesinin elle hasada göre önemli oranda düşük olmasına, makinalı hasadın elle hasada göre daha geç yapılması nedeniyle kütlü pamuğun başta nem ve güneş ışı̆̆ı gibi faktörlerden olumsuz yönde etkilenmesi neden olmaktadır.

Makinalı hasatta lif parlaklık derecesinin elle hasada oranla daha düşük olmasının bir başka nedeni; makinalı hasatta uygulanan yaprak döktürücünün (defoliant) etkisinden kaynaklanmış olabileceği sanılmaktadır. Nitekim benzer bulgular, Özkan ve Görmüş (2002) tarafından bildirilmektedir.

Özbek (2011), lif parlaklık derecesi açısından çeşitler arasında fark olduğunu, lif parlaklık derecesi ile hasat zamanı arasında doğrudan bir ilişkinin bulunduğunu, hasat zamanı geciktikçe yağış ve diğer çevresel faktörlere bağı olarak lif parlaklık derecesinin azaldığını bildirmiştir. Silvertooth (2001), açan kozaların uzun süreli veya ağır yağmura maruz kalması durumunda yağmurun elyafı beneklendireceğini, grilik ve sarılık değerlerini arttıracağını ayrıca Silvertooth ve ark. (1998), açan kozaların uzun süreli veya ağır yağışa maruz kalması durumunda yağmurun pamuğun benek alması ve grilik ve sarılık değerlerini arttıracağını ortaya koymuştur. Krieg (2002), hasat esnasındaki hava koşullarının renk ve yabancı madde içeriği üzerine direkt etkili olduğu, pamuk hasadının gecikmesi durumunda açan kozaların yağmur ve fırtına gibi hava koşullarına maruz kaldığında, yağışın elyafın renk derecesi üzerine olumsuz etkisinin olduğunu saptamıştır. Shurley ve ark. (2004), hasat zamanının lif renk derecesini hasat sırasındaki yüksek oransal nemin kütlü pamuk nem içeriğini direkt etkileyeceğini ve daha sonra, yüksek nemin hasat etkinliğini, lif parlaklığını azaltacağını, İşcan ve ark. (2002), makineyle toplanan pamuklarda Rd değerinin \%10 dolayında düştüğünü bildirmişlerdir. Elde edilen bulgular bu çalışmalarla benzerlik göstermekte olup, Karademir ve ark. (2005)' in makinalı hasatta lif parlaklık derecesinin elle hasada göre önemli oranda azaldığını bildiren çalışmasıyla 
uyum göstermiştir. Tüm lokasyonlarda, lokasyon içinde önemli varyasyonlar saptanmıştır.

Lif Sarılık Değeri (+b): Çizelge 4'de, elle hasatta $(7.78+b)$, makinalı hasatta $(7.22+b)$ göre önemli oranda daha yüksek Çizelge 4. Lif sarılık değeri (+b) kısa lif içeriği (\%) ve lifteki çepel sayısı (TrCnt) değ

\begin{tabular}{|c|c|c|c|c|c|c|c|c|c|}
\hline \multirow{3}{*}{ Lokasyon } & \multicolumn{3}{|c|}{ Lif Sarılık Değeri (+b) } & \multicolumn{3}{|c|}{ Kısa Lif İçeriği (\%) } & \multicolumn{3}{|c|}{ Lifteki Çepel Sayısı (TrCnt) } \\
\hline & \multicolumn{3}{|c|}{ Hasat Yöntemi } & \multicolumn{3}{|c|}{ Hasat Yöntemi } & \multicolumn{3}{|c|}{ Hasat Yöntemi } \\
\hline & Elle & Makine & Ortalama & Elle & Makine & Ortalama & Elle & Makine & Ortalama \\
\hline Söke & 7.92 & 7.05 & 7.48 & 6.72 & 6.82 & 6.77 & 9.75 & 63.00 & 36.37 \\
\hline Efeler & 7.77 & 7.52 & 7.65 & 6.85 & 7.45 & 7.15 & 9.50 & 43.25 & 26.37 \\
\hline Koçarlı & 7.90 & 7.25 & 7.57 & 6.90 & 6.42 & 6.66 & 12.50 & 59.50 & 36.00 \\
\hline Germencik & 7.62 & 6.85 & 7.23 & 6.25 & 7.07 & 6.66 & 7.75 & 57.75 & 32.75 \\
\hline İncirliova & 7.87 & 7.32 & 7.60 & 6.50 & 6.72 & 6.61 & 10.00 & 62.25 & 36.12 \\
\hline Nazilli & 7.60 & 7.37 & 7.48 & 6.40 & 6.62 & 6.51 & 15.75 & 62.75 & 39.25 \\
\hline Ortalama & $7.78 A^{*}$ & $7.22 \mathrm{~B}$ & 7.50 & 6.60 & 6.85 & 6.73 & $10.87 \mathrm{~B}$ & $58.08 \mathrm{~A}$ & \\
\hline LSD (\%5) & \multicolumn{3}{|c|}{ Hasat yöntemi:0.441 } & \multicolumn{3}{|l|}{-} & \multicolumn{3}{|c|}{ Hasat yöntemi:12.183 } \\
\hline
\end{tabular}

*Büyük harfler, lokasyonlara göre hasat yönteminin önem düzeyleri ve oluşturdukları gruplar

Silvertooth (2001), uzun süreli aşırı yağış durumunda elyafın yapraklara temas etmesi nedeniyle beneklenebileceğini, bitki kalıntılarının renk derecelerini önemli derecede etkileyeceğini, açan kozaların uzun süreli veya ağır yağmura maruz kalması durumunda yağmurun pamuğu beneklendireceğini, grilik ve sarılık değerlerini arttıracağını, Shurley ve ark. (2004), hasat zamanında yüksek nemin lif sarılık değerini etkileyeceğini, Özbek (2011), yıllara göre lif sarılık değerlerinin farklılık gösterdiğini, bunda çevresel faktörlerin, özellikle gerçekleşen yağışın etkili olabileceğini, pamuk çeşitlerinin lif sarılık değerleri yönünden farklık gösterdiğini, bu farklılıkta elyafın biyokimyasal yapısı yanında, çeşidin morfolojik özelliklerinin de etkili olabileceği, hasat zamanı geciktikçe lif sarılık değerlerinin doğrudan azaldığını, bu azalmada elyafın matlaşmasının önemli bir etken olduğunu bildirmişlerdir. Meredith (1986), renk değişimindeki varyasyonun \%79'unun, çevresel faktörlerden kaynaklandığı rapor etmiştir.

Karademir ve ark. (2005), lif sarılık (+b) değeri yönünden, hem hasat uygulamalarının hem de çeşitler arasındaki farklılığın önemli olmadığını bildirilmiştir. Görüldüğü üzere, elde edilen bulgular ile önceki çalışma sonuçları arasında benzerlik olduğu gibi farklılıklar da bulunmaktadır. Bu durumun genetik materyal ve hasat koşullarından kaynaklandığı düşünülmektedir.

Kısa Lif İçeriği (\%): Çizelge 4'de, lokasyon ortalamaları en yüksek Efeler (\%7.15) ve bunu azalan sıra ile Söke (\%6.77), Koçarlı (\%6.66), Germencik (\%6.66), Incirliova (\%6.61), Nazilli (\%6.51) lokasyonları izlemektedir. Hasat yöntemi yönünden ise makineli hasatta (\%6.85), elle hasada (\%6.60) göre önemsiz olmakla birlikte daha fazla kısa lif elde edilmiştir.

Hasat yöntemleri arasındaki farklılığın istatistiki olarak önemli olmamakla birlikte, elle hasatta kısa lif içeriği daha düşük olduğu makinalı hasatta ise bu değerin daha yüksek olduğu (Karademir ve ark., 2005) tarafından da bildirilmektedir.

Araştırmadaki bu özellikle ilgili Jost (2005), kısa lif içeriğinin genotiple birlikte, büyüme koşulları, hasat, çırçırlama lif sarılık değeri elde edilmiştir. Lokasyonlar arasında önemli farklılıkların bulunmama sebebi ekilen çeşidin aynı olması ve hasat zamanının yağışsız geçmesi gibi özellikler önemli rol oynamaktadır. koşulları ve yöntemlerine bağıı olduğunu, yüksek sıcaklıklarda kısa lif içeriğinin daha düşük olduğunu, Shurley ve ark. (2004), hasat zamanının kısa lif içeriğini etkilediğini, Özbek (2011), erken ve geç hasadın kısa lif indeksi değerleri arttırdığını, Bednarz ve ark. (2002), defoliant uygulamasının ve hasat zamanının kısa lif içeriğini etkilediğini bildirmişlerdir. Elde edilen bulgular ile önceki çalışma sonuçları arasında benzerlik olduğu gibi farklılıklarda bulunmaktadır.

Lif Çepel Sayısı (TrCnt): Çizelge 4.'de, makinalı hasatta (58.08), elle hasata (10.87) göre önemli oranda daha yüksek lif çepel sayısı elde edilmiştir. Hasat geciktikçe bitki parçalarının daha kırılgan olması ve lülelerin sarkarak yabancı madde bulaşmasının artması yabancı madde içeriğindeki artışlar da önemli rol oynadığı söylenebilir.

Kechagia ve Harig (1998), çevresel faktörlerin çepel sayısı ve yabancı madde oranını etkilediğini, buna karşın çeşidin yaprağının tüylü veya tüysüz olmasının yabancı madde sayısını değiştirebileceğini, Krieg (2002), hasat esnasındaki hava koşullarının renk ve yabancı madde içeriği üzerine direkt etkili olduğu, pamuk hasadının gecikmesi durumunda açan kozaların yağmur ve fırtına gibi hava koşullarına maruz kalabileceği, hava koşullarının öncelikle elyaf yabancı madde içeriği ve renk derecesi üzerine zararlı etkisi olduğunu, Shurley ve ark. (2004), hasat sırasındaki yüksek oransal nemin kütlü pamuk nem içeriğini direkt etkilediğini ve daha sonra, yüksek nemin yabancı madde içeriğini arttırdığını ve lif kalitesini azalttığını, Evcim (1999), Kaynak ve ark. (2000), Öz (2001), Öz ve Evcim (2002), Karademir ve ark. (2005) ve Sessiz ve ark. (2012)‘nin makinalı hasatta yabancı madde miktarının elle hasattaki yabancı madde miktarından daha fazla olduğunu bildiren bulgularıyla elde edilen bulgular benzerlik göstermektedir.

Lif Rengi (Colour Grade): Farklı yöntemlerle hasat edilmiş pamukların lif rengi değerlerine ilişkin ortalama sonuçlar Çizelge 5'de verilmiştir. 
Çizelge 5. Farklı yöntemlerle hasat edilmiş pamukların lokasyonlara ilişkin ortalama lif rengi değerleri

\begin{tabular}{lll}
\hline $\begin{array}{l}\text { Hasat Yöntemi ve Renk Dereceleri } \\
\text { Lokasyon }\end{array}$ & Elle & Makine \\
\hline Söke & $11-1$ & $21-1$ \\
Efeler & $21-1$ & $31-1$ \\
Koçarlı & $31-1$ & $41-1$ \\
Germencik & $21-1$ & $41-1$ \\
İncirliova & $21-1$ & $41-1$ \\
Nazilli & $31-1$ & $41-1$ \\
\hline
\end{tabular}

Çizelge 5'de, renk dereceleri değerlendirildiğinde tüm lokasyonlarda makina ile toplanan örneklerin 1-2 derece daha düşük çıktığı görülmektedir. Renk kodları incelendiğinde tüm lokasyonlarda gerek elle gerek makine ile toplanan örneklerin beyaz sınıfta olduğu, en kaliteli pamuğun her iki hasat yönteminde de Söke lokasyonunda olduğu görülmektedir.

Makinalı hasatta renk derecesinin daha düşük olmasına makinayla toplanan pamuklarda lif parlaklık derecesinin düşük, yabancı madde miktarının fazla olması etkilemektedir. Ayrıca makinalı hasat elle hasada göre daha geç yapıldığından, pamuklar elle hasada göre nem ve güneş ışığına daha çok maruz kalarak lif rengi daha çok matlaşmaktadır.

Lif rengi yönünden elde edilen bulgular Öz (2001), Öz ve Evcim (2002), Özbek (2011)'in bulgularıyla benzerlik göstermektedir.

\section{SONUÇ}

Makinalı hasadın lif inceliği ve lif sarılık değeri dışındaki incelenen özelliklere genelde olumsuz etkisi olduğu saptanmıştır, özellikle makinalı hasatta lif rengi tüm lokasyonlarda elle hasada göre 1-2 derece daha düşük çıkmıştır. Bu durum, makinalı hasadın elle hasada göre daha geç yapılması nedeniyle, pamuğun başta nem, çiğ, yağmur ve güneş ışığı gibi olumsuz çevre koşullarına daha fazla maruz kalarak lif renginin matlaşması ve çepel oranının fazla olmasından kaynaklanmaktadır.

Makinalı hasadın olumsuz etkilerini azaltabilmek için hasadın geciktirilmemesi, hasat makinasının ayarlarının iyi yapılması ve defoliant kullanımının istenilen şekilde yapılması gerekmektedir.

\section{KAYNAKLAR}

Anonim (2018) TUiK, Tarım Alet ve Makine İstatistikleri.

Bednarz CW, Shurley WD, Anthony WS (2002) Losses in Yield, Quality, and Profitability of Cotton From Improper Harvest Timing. Agronomy Journal 94:10041011.

Cathey W, Meredith WK, Williford JR, Anthony, WS (1986) Effect of Ethophen (prep) on Cotton Yield and Fiber Quality, Beltwide Cotton Conferences, Memphis, 1368-1369.

Evcim HÜ, Öz E (1997) Farklı Pamuk Çeşitlerinin Makinalı Hasadında Kantitatif Performansların Belirlenmesi, Tarımsal Mekanizasyon 17. Ulusal Kongresi, 790-797, Tokat.
Evcim HÜ (1996) Pamuk Toplama Makinaları ve Türkiye' de Pamuk Tarımının Makinalı Hasada Uyarlanması, Büyük Menderes Ovası ve Deltasında Tarım ve Çevre Sorunları Sempozyumu Bildiri Kitabı, 53-69.

Evcim HÜ, Öz E, Tekin B (2007) Kuyruk Mili Tahrikli, Traktöre Bindirilir iki Farklı Tip Pamuk Hasat Makinesinin Nicesel ve Nitesel iş Başarılarının Belirlenmesi. Tarım Makinaları Bilim Dergisi 3 (4): 270275.

Evcim HÜ, Öz E (1998) Comparison of Mechanical and Hand Harvesting of Cotton Regarding Lint Quality Factors Under Turkish Conditions. Proceedings of the World Cotton Research Conference 2, September 6-12, Athens- Greece, 1106-1108.

Evcim, Ü (1999) Türkiye Pamuk Tarımında Hasat Girişimleri ve Sonuçları. Türk Dünyasında Pamuk Tarımı, Lif Teknolojisi ve Tekstili I. Sempozyumu. 28 Eylül- 1 Ekim, Kahramanmaraş, 217-225.

Işık A, Sabancı A (1988) Pamuk Hasat Makinaları ve Çalışma Esasları, III. Ulusal Makina Teorisi Sempozyumu Bildiri Kitabı, $424-433$.

İşcan S, Gültekin E, Aklaş I, Özbilgili A, Yaşar M, Tepeli E, Karslı Z, Karataş T (2002) Pamuk Mekanizasyonu ve Çırçır Makineleri. T.C. Tarım ve Köy İşleri Bakanlığı, Adana Zirai Üretim işletmesi ve Personel Eğitim Merkezi Müdürlüğü, Adana.

Jost P (2005) Cotton Fiber Quality and the Issues in Georgia. Department of Crop and Soil Sciences Cooperative Extension Services. Bulletin 1289.

Karademir E, Karademir Ç, Başbağ S (2005) Güneydoğu Anadolu Bölgesinde Makinalı Hasadın Pamuğun Lif Teknolojik Özellikleri Üzerine Etkisi. Türkiye VI. Tarla Bitkileri Kongresi, 5-9 Eylül 2005, Antalya, I: 321-324.

Kaynak MA, Çopur O (1999). Makinalı Hasada Uygun Pamuk Yetiştirme Tekniği. HR.Ü.Z.F.Dergisi 3(1-2): 67-76.

Kaynak MA, Ünay A, Özkan İ, Başal H, Bayındır E (2000) Effect of Machine Picking on Agronomical and Technological Characteristics in Different Cotton Varieties (G. hirsutum L.). Proceedings, FAO- The Inter-Regional Cooperative Research Network on Cotton for The Mediterranean, 20-24 September 2000, Adana-Turkey,105-108.

Kechagia UE (1994) How Far We can Meet Spinners Needs. Paper Presented at ICAC Tecnical Seminar, Refice, Brazil. ICAC, Washington, DC.

Kechagia UE, Harig H (1998) New Perspectives in Improving Cotton Fiber Quality and Processing Efficiency. Proceedings of the World Cotton Research Conference-2, Athens, Greece, 85-93.

Krieg DR (2002) Fiber Quality Genetic and Environmental Affectors. Texsas Tech University Lubbock, TEXAS. [www.cottoninc.com/2002ConferencePresentations /Fiber Quality Genetics], Erişim Tarihi:20.07.2017

Mayfield WD (1996) Defoliation Effects on Harvesting and Ginning. Beltwide Cotton Conference,I:93-94. 
Meredith WRJr (1986) Fiber Quality Variation Among USA Cotton Growing Regions. Proc.Beltwide Cotton Conferance. National Cotton Council, 105-106.

Meredith WRJr (1984) Quantitative Genetics. In R.J. Kohel and C.F. Lewis (ed.) Cotton. Argon 24, USA, CSSA, Madison, WI,131-150

Metzer RB, Supak J (1997) Cotton Harvest-Aid Chemicals. Texas Agricultural Extension Service, Texas, B-1593, 37, 143-145.

Öktem T, Özdoğan E, Öncü S, Sokat Y (1999) Pamuk Liflerinde Gözlenen Bazı Hatalar. Türkiye Pamuk, Tekstil ve Konfeksiyon Sempozyumu. Tarımsal Ekonomi Araştırma Enstitüsü. 18-19 Mart, Gaziantep.

Ören MN, Yaşar B (2003) Türkiye'de Pamuk Hasat Makinesi Kullanımının Ekonomik ve Sosyal Açıdan Değerlendirilmesi. Türkiye VI. Pamuk, Tekstil ve Konfeksiyon Sempozyumu Bildirileri, 24-25 Nisan 2003, Antalya, 175-181,

Öz E (2001) Makinalı Pamuk Hasadının Pamuk Lif Kalitesi Üzerindeki Etkilerinin Çiftçi Koşullarında Belirlenmesi. Selçuk- Teknik Online Dergisi, 2(2).

Öz E, Evcim Ü (2002) Makinalı Hasadın Pamuk Lif Teknolojik Özellikleri Üzerindeki Etkilerinin Belirlenmesi. Ege Üniv. Ziraat Fak. Derg., (39)2:119-126.

Özbek N (2011) Pamukta (Gossypium hirsutum L.) Lif ve Tohum Özellikleri Arasındaki İlişkinin Saptanması. Adnan Menderes Üniversitesi Fen Bilimleri Enstitüsü, Doktora tezi, 153 Sayfa
TERZI H, KAYNAK MA

Özkan N, Görmüş Ö (2002) Harran Ovası Şartlarında, Yaprak Döktürücü Uygulama Dönemlerinin Pamuğun (Gossypium hirsutum L.) Bazı Kalite Özellikleri Üzerine Etkisi. M.K.Ü. Ziraat Fakültesi Dergisi, 7(1-2): 27-38.

Sessiz A, Esgici R, Eliçin AK, Gürsoy S (2012) Makinalı Hasadın Farklı Pamuk Çeşitlerinde Pamuk Lifinin Teknolojik Özelliklerine Etkisi. 27. Tarımsal Mekanizasyon Ulusal Kongresi, 5-7 Eylül 2012, Samsun, 154-159.

Shurley D, Bednarz C, Anthony S, Brown SM (2004) Increasing Cotton Yield, Fiber Quality, and Profit Through Improved Defoliation and Harvest Timeliness Issued in furtherance of Cooperative Exteödion Acts of May 8 and June 30, 1914, the University of Georgia College of Agricultural and Environmental Sciences and the U.S. Department of Agriculture cooperating.

Silvertooth JC (2001) Crop Management for Optimum Fiber Quality and Yield. The University of Arizona. Cooperative Extension.

Silvertooth JC, Norton ER, Brown PW (1998) Evaluation of Planting Date Effects on Crop Growth and Yield for Upland and Pima Cotton, 1997. https://repository.arizona.edu/bitstream/handle/101 50/210335/AZ1006-020-033.pdf. Erişim Tarihi: 05.03 .2018

Tuncer K, Işık A (1999) Makineli Pamuk Hasadı ve Türkiye'deki Gelişmeler. Türk Dünyasında Pamuk Tarımı Lif Teknolojisi ve Tekstil 1. Sempozyumu. 28 Eylül-1 Ekim Kahramanmaraş. 
